\title{
A situação militar do Brasil na América do sul - conselho de defesa sul-americano e a necessidade de fortalecimento do poder militar*1
}

\author{
Antonio Rafael Siqueira Santos ${ }^{2}$
}

\section{Resumo}

Neste artigo abordamos os principais Organismos Regionais de Defesa e os acontecimentos que os influenciaram, como o medo gerado pela Segunda Guerra Mundial e a influência estadunidense com a Doutrina Monroe. Estes organismos possuem, de maneira geral, a função de fortalecer a cooperação na área da defesa; facilitar o intercâmbio de informação e experiência entre os países e criar espaços para foros de debates relacionados à segurança e defesa.

Abordamos, também, a criação do Conselho de Defesa Sul-Americano cujas negociações iniciaram-se no ano de 2008, com o propósito de estender a cooperação para os campos de defesa e segurança, para, assim, atingir um maior grau de estabilidade regional, visto que a segurança de um país é condicionada pelo grau de estabilidade da região em que se situa. O Conselho de Defesa Sul-Americano é composto pelos Ministros de Defesa, ou seus equivalentes, dos países membros da UNASUL, e tem como objetivos gerais a criação de uma zona de paz, a construção de uma identidade sul-americana e a geração de consensos para fortalecer a cooperação regional no campo de defesa.

Os países da América do Sul possuem certas assimetrias políticas e sociais, o que dificulta a atuação de organismos regionais, entretanto é necessária a integração regional no campo da defesa e segurança para que os países sul-americanos

* Recebido em 28.05.2010

Aprovado em 30.06.2010

1 Palestra proferida no curso de Extensão em Defesa Nacional, no dia 31 de maio de 2010, no Auditório do Bloco I do UNICEUB

2 Capitão-de-Mar-e-Guerra (FN-RM-1). Assessor do Departamento de Política e Estratégia (DPE). Secretaria de Política, Estratégia e Assuntos Internacionais - MD E-mail de contato: rafael.santos@defesa.gov.br 
possam, juntos, encontrar melhores soluções para seus problemas em comum e, assim, se tornarem mais fortes e estáveis.

Palavras chaves: Integração; Cooperação; Defesa; América do Sul; Estabilidade; Segurança.

\section{Introdução}

Este ensaio tem como objetivo apresentar as considerações relativas aos Organismos Regionais de Defesa, tendo como foco os aspectos da integração e da cooperação regional na América do Sul que contribuem para a manutenção de um ambiente de paz e segurança, o que farei tomando por base o Conselho de Defesa Sul-Americano (CDS).

\section{Síntese histórica}

Os movimentos de independência ocorridos no continente americano no início do século XIX causaram a fragmentação dos antigos vice-reinos espanhóis. Apesar do surgimento de tentativas de construção, ao sul, de uma "grande Argentina" englobando os territórios que hoje corresponde à própria Argentina, Paraguai, Bolívia e parcela do Peru e do Chile, e, ao norte, da República da Grã-Colômbia, correspondendo hoje à Venezuela, Colômbia, Panamá e Equador - o ideal de Simon Bolívar, só a grande colônia portuguesa, o Brasil, manteve-se unida. Os conflitos daí oriundos são os responsáveis pelo acirramento de rivalidades e desconfianças, algumas delas ainda hoje existentes.

\subsection{A influência americana}

A aprovação da "Doutrina Monroe" pelo Congresso estadunidense, em 1823, com a intenção de conter novas investidas européias foi o início de um longo processo de influência norte-americana no continente, passando pela política do 
"Big Stick", com intervenções militares, e pela expansão dos seus interesses econômicos e estratégicos, principalmente na América Central e Caribe.

O Congresso do Panamá, em 1824, e em 1890 a 1ª Conferência Internacional Americana e a União Pan Americana, esta última, embrião da Organização dos Estados Americanos (OEA), são os primeiros movimentos de criação de Organismos unindo os países do continente americano.

\subsection{A $2^{\mathrm{a}}$ guerra mundial}

Depois da invasão da França e Holanda pela Alemanha em 1940, os Ministros das Relações Exteriores se reuniram em Havana e adotaram a declaração de "Assistência Recíproca e Cooperação Defensiva das Nações Americanas", receosos de um ataque das potências que formavam o "Eixo", às possessões holandesas e francesas no continente e que os envolvessem na guerra. A agressão a um seria uma agressão a todos.

Em 1942, sob impacto do ataque japonês a Pearl Harbor, foi criada a Junta Interamericana de Defesa (JID), como órgão de "preparação e recomendação aos Estados para a legítima defesa do continente”. Aqui identificamos a ameaça comum que rondava os países.

Em 1947, foi assinado o Tratado Interamericano de Assistência Recíproca (TIAR), conhecido como Tratado do Rio que regula medidas diplomáticas e militares para a defesa coletiva do hemisfério. Em 1948, foi criada, pelo Tratado de Bogotá, a Organização dos Estados Americanos (OEA) como organismo multilateral regional. Alguns analistas consideram esses eventos o coroamento da Doutrina Truman no continente - a garantia da assistência dos EUA na luta contra o comunismo.

Nas décadas de 70 e 80 a influência estadunidense ainda se fazia presente com o apoio aos governos militares na região. Surge então, nas sociedades latinoamericanas, a percepção da inexistência de ameaças concretas à segurança 
nacional. Os EUA passam a adotar a política de "hegemonia benévola", mas na prática, a velha tática de "dividir para governar", que consistia no estabelecimento de interesses comuns com os principais estados suplantando quaisquer outros oriundos da relação entre sócios regionais.

Por fim, apesar do insucesso da Área de Livre Comércio das Américas (ALCA), a celebração de acordos bilaterais entre os EUA e os países sul americanos, com exceção dos membros plenos do Mercosul e Venezuela, nos leva a considerar que a estratégia estadunidense adotada pelo Governo Bush, principalmente no seu primeiro governo, foi a desestruturação do processo de integração da América do Sul.

\section{Mecanismos de segurança hemisférica}

Apesar da síntese acima não respaldar completamente a conclusão que se segue, não é difícil verificar que a região esteve marcada pelas crises domésticas, instabilidade política, pelos contenciosos territoriais, por rivalidades históricas e pela permanente influência norte-americana.

A seguir destacarei os principais mecanismos regionais de defesa que proporcionam fóruns para discussões políticas de segurança e de defesa:

\subsection{Tratado interamericano de assistência recíproca (TIAR)}

Assinado em 1947, estabelece a defesa coletiva do Hemisfério: o ataque a um de seus países pode ser considerado como um ataque a todos os demais. $\mathrm{O}$ TIAR consolidou um mecanismo de defesa das Américas frente a uma ameaça comum que representava o "comunismo” na época da Guerra Fria.

Nos atentados terroristas de 11 de setembro de 2001, o Brasil evocou o Tratado em uma Reunião de Ministros das Relações Exteriores da OEA, em 21 de setembro do mesmo ano. Na oportunidade, o Brasil reiterou a posição de que o 
TIAR ainda constitui o marco jurídico adequado para a discussão e a definição de linhas de ação de combate ao terrorismo no plano regional. Essa atitude, marcada de simbolismo, evidenciava, naquele momento, que era uma questão de defesa e de segurança um país dispor de aliados confiáveis em todos os momentos, destacando a importância que o Brasil atribui ao Tratado.

O Brasil considera que o TIAR é um instrumento válido para a cooperação na área de defesa no plano hemisférico.

\subsection{Organização dos estados americanos (OEA)}

A OEA, configurada nos moldes atuais desde 1948, congrega os países das três Américas com o fim de fortalecer a cooperação e desenvolver interesses comuns, aí inclusos os campos de segurança e defesa. Suas últimas e mais importantes reuniões para os temas que aqui nos interessam são a "Conferência Especial sobre Segurança" (Out./2003) e a "Cúpula Extraordinária das Américas" (Jan./2004). Apesar do caráter distinto destas, ambas as reuniões apresentam pontos comuns de contato com respeito à segurança hemisférica.

\subsection{Junta interamericana de defesa (JID)}

Ao longo de grande parte de sua existência, a JID viveu sob inspiração de um mundo bipolar e assim orientou seus trabalhos ao preparo e ao planejamento da defesa do continente contra um inimigo comum.

A JID e o Colégio Interamericano de Defesa, dirigido pela JID, facilitam o estabelecimento de redes, permitindo que os militares que enfrentam diferentes situações troquem experiências e aprendam com os demais.

Em 2006, foi apresentado o novo regulamento da JID estabelecendo seu vínculo jurídico e institucional com a OEA e definindo como seu principal propósito - o de prestar à OEA e seus Estados-membros serviços de assessoramento 
técnico, consultivo e educativo em assuntos relacionados a temas militares e de defesa no hemisfério, a fim de contribuir para o cumprimento da Carta da OEA. Posicionamento que foi defendido pelo Brasil.

Ao analisar o contexto em que foram criados os sistemas de segurança do continente americano acima descritos, a primeira impressão que se tem é a de uma aliança militar. Entretanto, alianças são caracterizadas por ameaças reais ou objetivos bem definidos e esses organismos foram criados em um ambiente no qual os EUA, após o término da Segunda Guerra Mundial, passou a se preocupar com o combate ao comunismo.

\subsection{Conferência de ministros da defesa das américas (CMDA)}

Para fazer frente às "novas ameaças", começou a ter lugar, a partir de 1995, as CMDA, tendo sido reconhecidas na Conferência Especial sobre Segurança da OEA como "um espaço apropriado para promover o conhecimento recíproco, a confiança mútua, o diálogo e a transparência em matéria de defesa”.

A CMDA foi criada com a finalidade de constituir um foro de debates para o intercâmbio de experiências entre os Ministros da Defesa do continente americano. Esse encontro ministerial é a principal instância de reunião do setor de defesa no continente americano e seu objetivo central é o debate, a análise e o intercâmbio de experiência dos temas que derivam da proposta efetuada pelo país que está sediando a Conferência e do consenso entre os membros.

Foram realizadas as seguintes Conferências de Ministros da Defesa das Américas:

\begin{tabular}{|c|c|c|}
\hline Conferência & Ano & Local \\
\hline I CMDA & 1995 & Williamsburg \\
\hline II CMDA & 1998 & Bariloche \\
\hline III CMDA & 1999 & Cartagena \\
\hline IV CMDA & 2000 & Manaus \\
\hline V CMDA & 2002 & Santiago \\
\hline VI CMDA & 2004 & Quito \\
\hline VII CMDA & 2006 & Manágua \\
\hline VIII CMDA & 2008 & Banff \\
\hline
\end{tabular}


A IX CMDA está prevista para ser realizada de 21 a 26 de novembro de 2010 em Santa Cruz de La Sierra, na Bolívia.

\section{Conselho de defesa sul-americano}

A criação de um Conselho de Defesa Sul-Americano deu prosseguimento, no seio da União das Nações Sul-Americanas, às ações iniciadas na Primeira Reunião de Ministros da Defesa da Comunidade Sul-Americana de Nações (CASA).

Em 2008, por iniciativa do Brasil, foram entabuladas negociações com autoridades governamentais da América do Sul, com o propósito de criar, no âmbito da UNASUL, um foro que reunisse os titulares das pastas de defesa de todos os países da região.

Buscava-se, naquele momento, estender ao campo da defesa os avanços já obtidos em outras áreas de cooperação regional, angariando apoio para a proposta de criação de um arranjo em que prevalecessem ações de cooperação no campo da segurança e da defesa, e em que também se fizessem presentes iniciativas que contemplassem estímulos à consolidação de uma base industrial de defesa que atendesse às necessidades dos países integrantes.

Além disso, tal empreendimento foi concebido sob a perspectiva de que a segurança de um país é afetada pelo grau de instabilidade da região em que ele se situa - no caso, a América do Sul. Portanto, com vistas a alcançar um almejado grau de estabilidade regional, é desejável que ocorram: o consenso, a harmonia política, e a convergência de ações entre os países sul-americanos. Essas são condições indispensáveis, que favorecem o desenvolvimento econômico e social e que, conseqüentemente, tornarão a região mais coesa e mais forte.

Na ocasião, já se avaliava também que um Conselho de Defesa SulAmericano (CDS) traria consigo o benefício adicional de contribuir para a formação de uma identidade regional no campo da defesa, levando em conta as características locais (vertentes platina, andina, amazônica, atlântica, caribenha e 
pacífica) e articulando uma visão fundamentada em valores e princípios comuns de interesse dos Estados.

Essa visão particular em matéria de defesa é de interesse dos governos da UNASUL, no sentido em que ela reforçará a confiança mútua, contribuindo para afastar percepções equivocadas e aportando, ao mesmo tempo, maior estabilidade e segurança à região. A discussão de questões relacionadas com a defesa de um ou mais Estados-Membros pode, ademais, contribuir para o alívio de tensões na América do Sul.

Importa destacar que em nenhum momento foi considerada a constituição de uma aliança militar de defesa sul-americana, no sentido clássico, do tipo "OTAN do Sul”, ou outro tipo de arranjo que possa, a priori, articular ações no plano operacional, como uma "Força Sul-Americana de Paz". Tampouco se pretendeu criar um "Conselho de Segurança Sul-Americano", uma vez que as atribuições do Conselho de Segurança das Nações Unidas, no campo da paz e da segurança internacionais, não se confundem com os mandatos dos órgãos regionais e sub-regionais.

Assim, terminado o período de consulta aos países sul-americanos e diante das reações positivas dos Ministérios de Defesa da região, o Presidente Lula apresentou, por ocasião da cúpula extraordinária de Chefas e Chefes de Estado e de Governo da UNASUL realizada em maio de 2008 em Brasília, a proposta de criação do Conselho de Defesa Sul-Americano, observando o objetivo estatuído no Tratado Constitutivo da UNASUL, assinado naquela ocasião, e que consiste em construir, de maneira participativa e consensual, um espaço de integração e união entre seus povos. Por sugestão da Presidenta Michelle Bachelet, foi criado um Grupo de Trabalho para aprofundar a idéia e elaborar uma proposta de Estatuto para o CDS.

Ao longo de 2008, o Grupo de Trabalho se reuniu em quatro ocasiões em Santiago. Convocados pelo Ministério da Defesa do Chile, país que exerce a Presidência Pró Tempore da UNASUL, aqueles encontros - que contaram com a participação ativa de representantes dos Ministérios de Defesa e de Relações Exteriores dos doze países sul-americanos - foram marcados por intensos debates, estudos e negociações, sob a premissa de harmonizar os interesses de todos os participantes. Resultou dessas reuniões, a última das quais ocorreu em dezembro de 2008, um documento contendo os 
princípios, os objetivos gerais e específicos e a estrutura de funcionamento do Conselho a ser criado. Em suma, uma proposta consensuada de estatuto do CDS.

A proposta do Grupo de Trabalho foi submetida à aprovação das Chefas e Chefes de Estado e de Governo dos países-membros da UNASUL em 16 de dezembro de 2008, ao ensejo de nova cúpula extraordinária, desta vez realizada em Salvador, na Bahia. Com o aval dos mandatários, o CDS foi então formalmente estabelecido.

O Conselho foi estabelecido com o propósito de complementar os foros existentes, a exemplo dos encontros bilaterais de Chefes de Estados-Maiores e de Comandantes de Forças, da Junta Interamericana de Defesa, da Comissão de Segurança Hemisférica, da Conferência de Ministros da Defesa das Américas, da Conferência dos Exércitos Americanos, da Conferência Naval Interamericana e do Sistema de Cooperação entre as Forças Aéreas Americanas.

Terá ainda como atributo a aptidão para preencher a lacuna existente na análise conjunta de questões políticas e estratégicas de defesa, ensejando um debate mais amplo sobre as realidades global e hemisférica, sob a ótica da América do Sul. Tal exame levará em conta as perspectivas de países democráticos que compartilham ambiente regional e cultural, distantes dos principais focos de tensão mundial, com baixos gastos em defesa em relação às demais regiões e com conflitos interestatais mantidos em níveis mínimos.

\subsection{Objetivos gerais}

Conforme previsto em seu documento de criação, o Conselho de Defesa Sul-Americano tem os objetivos gerais de:

consolidar a América do Sul como uma zona de paz, base para a estabilidade democrática e o desenvolvimento integral de nossos povos, e como contribuição à paz mundial;

construir uma identidade sul-americana em matéria de defesa, que leve em conta as características sub-regionais e nacionais e 
que contribua para o fortalecimento da unidade da América Latina e do Caribe; e gerar consensos para fortalecer a cooperação regional em matéria de defesa.

\subsection{Objetivos específicos}

São objetivos específicos:

- $\quad$ avançar gradualmente na análise e discussão dos elementos comuns de uma visão conjunta em matéria de defesa;

- $\quad$ promover o intercâmbio de informação e análise sobre a situação regional e internacional, com o propósito de identificar os fatores de risco e ameaça que possam afetar a paz regional e mundial;

- contribuir para a articulação de posições conjuntas da região em foros multilaterais sobre defesa, no marco do artigo 14 do Tratado Constitutivo da UNASUL3;

avançar a construção de uma visão compartilhada a respeito das tarefas de defesa e promover o diálogo e a cooperação preferencial com outros países da América Latina e do Caribe;

fortalecer a adoção de medidas de fomento da confiança e difundir as lições aprendidas;

promover o intercâmbio e a cooperação no âmbito da indústria de defesa;

estimular o intercâmbio em matéria de formação e capacitação militar, facilitar processos de treinamento entre as Forças Armadas e promover a cooperação acadêmica entre os centros de estudo de defesa;

3 Artigo 14 - Diálogo Político - A concertação política entre os Estados Membros da UNASUL será um fator de harmonia e respeito mútuo que afiance a estabilidade regional e sustente a preservação dos valores democráticos e a promoção dos direitos humanos. Os Estados Membros reforçarão a prática de construção de consensos no que se refere aos temas centrais da agenda internacional e promoverão iniciativas que afirmem a identidade da região como um fator dinâmico nas relações internacionais. 
compartilhar experiências e apoiar ações humanitárias, como a desminagem, a prevenção e mitigação de desastres naturais e a assistência às suas vítimas;

compartilhar experiências em operações de manutenção de paz das Nações Unidas;

intercambiar experiências sobre os processos de modernização dos Ministérios de Defesa e das Forças Armadas; e promover a incorporação da perspectiva de gênero no âmbito da defesa.

\subsection{Estrutura e funcionamento}

O Conselho de Defesa Sul-Americano é integrado pelos Ministros de Defesa, ou seus equivalentes, dos países membros da UNASUL.

As delegações nacionais serão compostas por altos representantes de Relações Exteriores e de Defesa e pelos assessores cuja participação os Estados Membros considerem necessária.

O Conselho terá uma instância executiva, composta pelos Vice-Ministros de Defesa, ou seus equivalentes.

A Presidência caberá ao Ministro da Defesa do país que ocupe a Presidência Pro-Tempore da UNASUL e terá a responsabilidade de coordenar as atividades do Conselho.

O Conselho poderá constituir grupos de trabalho para examinar temas específicos e formular sugestões ou recomendações e realizará reuniões ordinárias anualmente, segundo o critério de rotação da Presidência Pro Tempore da UNASUL.

Os acordos serão adotados por consenso, conforme o artigo 12 do Tratado Constitutivo da UNASUL, e a instância executiva do Conselho se reunirão a cada seis meses, sem prejuízo de reuniões extraordinárias, para elaborar o plano de ação anual. 
A Presidência poderá convocar reuniões extraordinárias a pedido de, pelo menos, metade de seus Estados-Membros.

\subsection{Plano de ação 2009-2010}

O processo de transição entre a gênese desse importante instrumento de integração sul-americana e seu amadurecimento foi bastante curto: formalmente criado em dezembro de 2008, o CDS já realizava sua primeira reunião, de Vice-Ministros de Defesa, nos dias 28 e 29 de janeiro de 2009, em Santiago do Chile. Nesse encontro, foi concluída a elaboração de uma proposta de Plano de Ação para o período 2009-2010.

O objetivo desse primeiro plano consiste em promover um conjunto de iniciativas exeqüíveis em curto e médio prazos, que possuam a propriedade de conferir legitimidade e visibilidade ao Conselho. O documento é uma agenda ampla para a construção de uma identidade sul-americana na área de defesa, que se expressará, de maneira gradual e flexível, por meio de iniciativas divididas em 4 áreas:

Na primeira delas, afeta à política de defesa, estão previstas:

a criação de uma rede para intercambiar informação sobre políticas de defesa;

a realização de um seminário sobre modernização dos Ministérios de Defesa;

- $\quad$ o compartilhamento e a promoção de maior transparência no tocante a informações sobre gastos e indicadores econômicos de defesa;

- $\quad$ a definição de enfoques conceituais;

- $\quad$ a identificação de fatores de risco e ameaças que possam afetar a paz regional e mundial;

a criação de um mecanismo para contribuir para a articulação de posições consensuadas da região em foros multilaterais sobre defesa; e 
a confecção de uma proposta de estabelecimento de mecanismo de consulta, informação e avaliação imediata frente a situações de risco para a paz de nossas nações.

$\mathrm{Na}$ área de cooperação militar, ações humanitárias e operações de paz serão executadas:

o planejamento de um exercício combinado de assistência em caso de catástrofe ou desastres naturais;

a organização de uma conferência sobre lições aprendidas em operações de paz, enfatizando tanto os aspectos relacionados ao âmbito interno como ao multilateral;

a elaboração de um inventário das capacidades de defesa que os países podem oferecer para apoiar as ações humanitárias; e

a promoção do intercâmbio de experiências nesse campo, a fim de estabelecer mecanismos de resposta imediata para a ativação de recursos frente a situações de desastres naturais.

$\mathrm{Na}$ área de indústria e tecnologia de defesa, foram contempladas:

a elaboração de um diagnóstico da indústria de defesa dos países-membros, identificando capacidades e áreas de associação estratégicas, com o fito de promover a complementaridade, a investigação e a transferência tecnológica; e

- a promoção de iniciativas bilaterais e multilaterais de cooperação e produção relacionadas à indústria de defesa, no marco das nações integrantes do CDS.

Finalmente, na área de formação e capacitação, estão previstos:

a elaboração de um registro de academias e centros de estudo de defesa e de seus programas, e a criação de uma rede sul-americana destinada à capacitação e à formação em defesa, tudo isso visando 
o intercâmbio de experiências e o desenvolvimento de programas conjuntos;

a confecção de uma proposta de programas de intercâmbio docente e estudantil, a homologação, a avaliação e a disseminação de estudos, o reconhecimento de títulos e a concessão de bolsas para as instituições existentes;

a criação de um Centro de Estudos Estratégicos de Defesa (CEED) do Conselho de Defesa Sul-Americano na Argentina; e

a promoção, durante o mês de novembro de 2009, no Rio de Janeiro, do Primeiro Encontro Sul-Americano de Estudos Estratégicos (I ESEE), evento realizado na Escola Superior de Guerra do Brasil.

\section{Considerações finais}

$\mathrm{Na}$ América do Sul, as atuais assimetrias políticas e sociais e a influência de líderes populistas dificultam a dinâmica dos organismos regionais, mas é nesse ambiente que buscamos a convivência e a inserção de todos os estados. As circunstâncias históricas, sociais e políticas, favorecem a aproximação entre os países que a constituem e conduzem a interesses convergentes.

A redução dos índices de miséria e de exclusão social vem ocorrendo em todos os Estados sul-americanos, em maior ou menor escala, com um aumento dos percentuais dos PIB em despesas sociais.

As instabilidades decorrentes dos processos de consolidação democrática e de integração regional não comprometem a confiança recíproca, a solução negociada de potenciais conflitos e a consequente aproximação dos países da região.

Com essa compreensão têm sido promovidas reuniões dos diversos mecanismos regionais e sub-regionais que tratam da segurança e da defesa, para debater formas de cooperação e aprofundar iniciativas voltadas para o fortalecimento da segurança. 
Ao participar, efetivamente, de todos os foros regionais e sub-regionais na América do Sul, o Brasil apresenta-se como elemento indutor, promovendo e estimulando a realização de reuniões no âmbito desses foros.

O Brasil considera que tem a responsabilidade de participar como elemento catalisador das iniciativas de integração na América do Sul, buscando criar o ambiente de cooperação necessário para estabilidade, paz e maior segurança de todos e convivendo harmonicamente com os seus vizinhos.

Tal participação proporciona ao País a oportunidade única de interagir com interesses de todos os Estados do subcontinente, o que acaba por facilitar sua atuação integradora em conferências de âmbito regional ou hemisférica, a exemplo da União de Nações Sul-Americanas.

Esse é o intuito que motivou a proposta de criação do Conselho de Defesa Sul-Americano, no âmbito da UNASUL: um foro cooperativo, equilibrado e democrático, onde as decisões são tomadas por consenso; um foro que respeite as diversidades, os anseios, os valores e as tradições de cada nação e, sobretudo, que seja capaz de se adaptar às novas situações.

A importância de conferências e reuniões dessa magnitude reside, sobretudo, na oportunidade de reafirmar conceitos e consagrar princípios de segurança e de defesa.

Vislumbra-se que a existência de uma visão regional reforçará a confiança mútua e afastará percepções equivocadas por meio do maior entrosamento, aportando assim maior previsibilidade quanto a possíveis situações de crise.

Uma concertação no âmbito regional sobre temas políticos e estratégicos, de segurança e defesa, poderá acelerar a formação de consensos que, ao serem apresentados em bloco, facilitarão o encaminhamento de soluções para problemas de interesse comum. 
Muito embora eu não tenha tocado na crise financeira que o mundo atravessa, ela cria um novo cenário político e econômico internacional que pode ensejar uma competição econômica acirrada, novos alinhamentos estratégicos e o agravamento de antigos antagonismos ou o surgimento de novos.

Finalmente, ao apreciar todos os aspectos apresentados, pode-se concluir que a integração da América do Sul a tornará mais estável e coesa, dotada de maior poder na interlocução com parceiros extra-regionais, o que, com certeza, contribuirá para a paz e a segurança regionais. Somente a integração da América do Sul a tornará mais estável, mais coesa e mais forte. 